\title{
Uncertainties of the transfer of radionuclides in terrestrial ecosystems
}

\author{
C. Rommens, P. Renaud, F. Vray, D. Louvat and B. Crabol \\ IPSN/DPRE, CE Cadarache, 13105 Saint-Paul-lez-Durance, France
}

\begin{abstract}
The Nord-Cotentin radioecological study was conducted in different stages. First, an assessment tool was developed and implemented to estimate the number of leukaemia radio-induced by the operation of nuclear facilities of the La Hague site (Nord-Cotentin region, France). Then, an uncertainty analysis was initiated to verify if the confidence intervals around the best estimate previously calculated allows to confirm the low impact of the nuclear facilities. The modelling of the terrestrial ecosystems was especially studied because of the paucity of results of measurements. That is also why the methodology built to reconstruct the statistical laws for each parameter of the model mixes the bibliographic knowledge and exploitation of a national database of environmental measurements. The application of this methodology for up to forty parameters shows that the possibility of fitting an accurate distribution such as a normal or a lognormal law is strongly linked with the availability and the number of measured data.
\end{abstract}

\section{INTRODUCTION}

There has been a great concern for a number of years about observations of an increased incidence of childhood leukaemia around nuclear sites and the possibility that this might be linked to operations at the sites [1]. The Nord-Cotentin radioecological study was carried out by an experts working group commissioned by the French Minister of the Environment and the Secretary of State for Health and Health Insurance to consider this possibility for the Nord-Cotentin region of France [2]. The nuclear fuel reprocessing plant of $\mathrm{La}$ Hague is located in this region together with other nuclear installations : the nuclear power plant of Flamanville, a shallow-land waste disposal and naval dockyards at Cherbourg. The aim of the study was to estimate the exposures from all sources of ionising radiation and the corresponding risks of radiation induced leukaemia for young people aged from 0 to 24 year living in the region. This paper focuses on the development of the modelling of the transfer of radionuclides in ferrestrial ecosystems and on the methodology and the results of the corresponding uncertainty study.

In carrying out the Nord-Cotentin study it was considered important to involve as many interested parties as possible to ensure that the methods and data were subject to scrutiny throughout. Therefore, the working group involved 50 experts from a range of organizations including regulators, government experts, the site operators, experts from non-governmental groups, including environmental groups, and experts from outside France. An important aim was to get consensus from all of these different inputs, or at least to be able to explain any areas of disagreement. That is why this radioecological study was finally constituted of different stages, each of whom ended by the redaction of a report which contains recommendations for further efforts to overcome the limits of the work already done.

\section{ASSESSMENT METHODOLOGY}

The first step of the study from 1996 to 1999 was focused on the development of a modelling of the transfer of radionuclides from contaminant sources to man in order to calculate the risk of leukaemia induced by the operation of the local nuclear facilities. The terrestrial part of the modelling took into account the main transfer pathways (dispersion in the atmosphere, deposition on the ground, direct interception of radionuclides by plants, soil transfer of radionuclides via roots and transfer to animals and 
foodstuffs) but also searched to model more exotic pathways such as spreading of contaminated algae in fields or influence of sea sprays (figure 1).
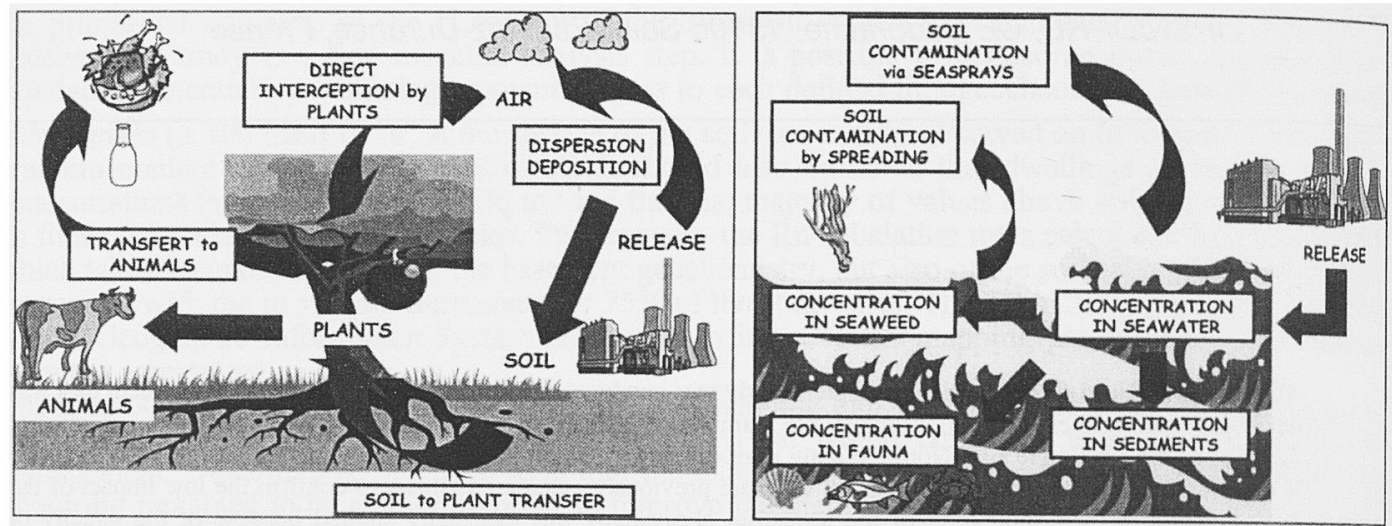

Figure 1: The modelling of transfer in the ecosystems

The second step of the study which began in 2000 , was an uncertainty analysis related to the whole risk assessment to verify if the confidence interval around the best estimate already calculated allows to confirm the low impact of the nuclear installations. The transfer model related to terrestrial ecosystems was especially studied because of the scarcity of environmental measurements in the vicinity of the La Hague site. This lack of data led to build a methodology who mixes bibliographic knowledge and exploitation of a national data base of measurements in the environment (figure 2).

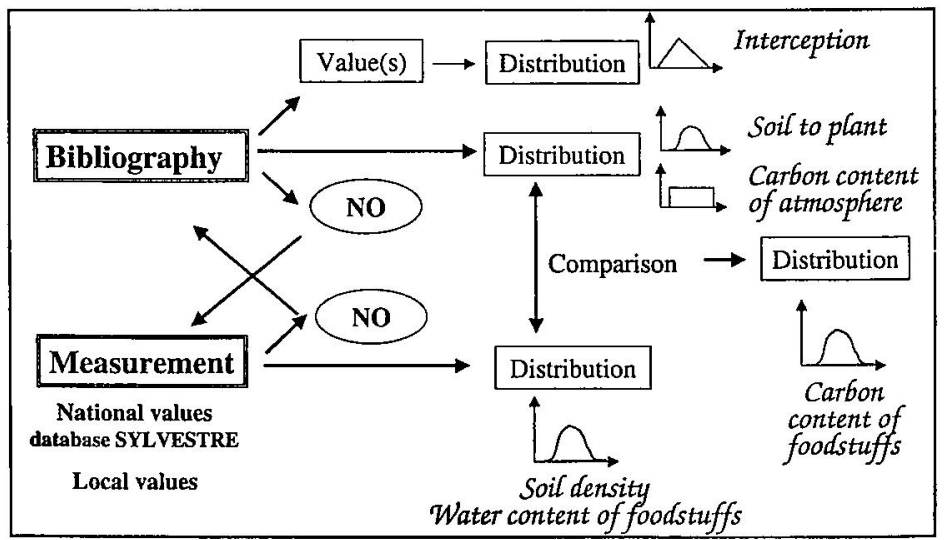

Figure 2: Methodology to build the statistical laws for each transfer parameter

The data base used for this study (SYLVESTRE) is developed by IPSN to collect all measurement results obtained in the environment and especially in the vicinity of the French nuclear power plants. At the time of the study, SYLVESTRE contains about 190,000 data.

The methodology described Figure 2 was applied to the main parameters of the terrestrial transfer model. A simple criterion was chosen to limit the study to a reasonable quantity of parameters and only parameters contributing to more than $1 \%$ of the leukaemia risk calculated in the Nord-Cotentin study were studied. The plants and the animals taken into account by the uncertainty study are root vegetables, fruits vegetables, leafy vegetables, grass, hay, maize fodder, different kinds of meats (beef, pork, poultry 
and eggs) and cow's milk. Distributions for parameters radionuclide dependent are proposed for strontium 90 and technetium 99. These radionuclides were chosen because of their important contribution to the assessment of leukaemia risk. Uncertainties associated with the particular cases of tritium and carbon 14 were also studied because of their specific interaction to biological matrix.

\section{RESULTS AND DISCUSSION}

The risk modelling took into account 80 radionuclides, 30 years of radioactive releases and transfers into the environment and four exposed age groups for the site-specific situation of the Nord-Cotentin region.

Then, the uncertainty analysis focused on the most sensitive parameters of the risk modelling. Different analyses were implemented with respect of the availability of data and in particular of sitespecific measurement results.

\subsection{Parameters with measurements results}

This case stand for atmospheric transfer coefficient (CTA) which is the main parameter of radionuclides dispersion modeling into the atmosphere, the water and carbon contents of the various foodstuffs studied and the soil to plant transfer factor.

\subsubsection{Atmospheric transfer coefficient}

The knowledge of local dispersion of radionuclides into the atmosphere was obtained through monitoring campaigns of ${ }^{85} \mathrm{Kr}$ activities in air in the vicinity of the reprocessing center of COGEMA at La Hague [3]. 34 results of measurements were available for this site-specific radionuclide and can be compared with the corresponding activities of ${ }^{85} \mathrm{Kr}$ released by the stacks. The ratios of measured atmospheric transfer coefficient to calculated atmospheric transfer coefficient for these 34 meteorological situations gave description of the variability of the dispersion in the atmosphere. This variability can be represented by a lognormal statistical law (mean : 2.41 and standard deviation : 1.52) of the ratios (measured atmospheric transfer coefficient / calculated atmospheric transfer coefficient). Measurements were available at La Hague site only for the normal condition of diffusion so it was assumed that the results obtained can be extended to other meteorological conditions.

\section{1 .2 Water content of foodstuffs}

The water content of foodstuffs is the main parameter of the specific activity model used to calculate the transfer of tritium in the terrestrial ecosystems. These parameter is not site-specific and so the numerous data available in the database SYLVESTRE for this parameter allowed to reconstruct its variability for each food category by fitting a normal law on SYLVESTRE data. The case of the fruits vegetables is illustrated Figure 3.
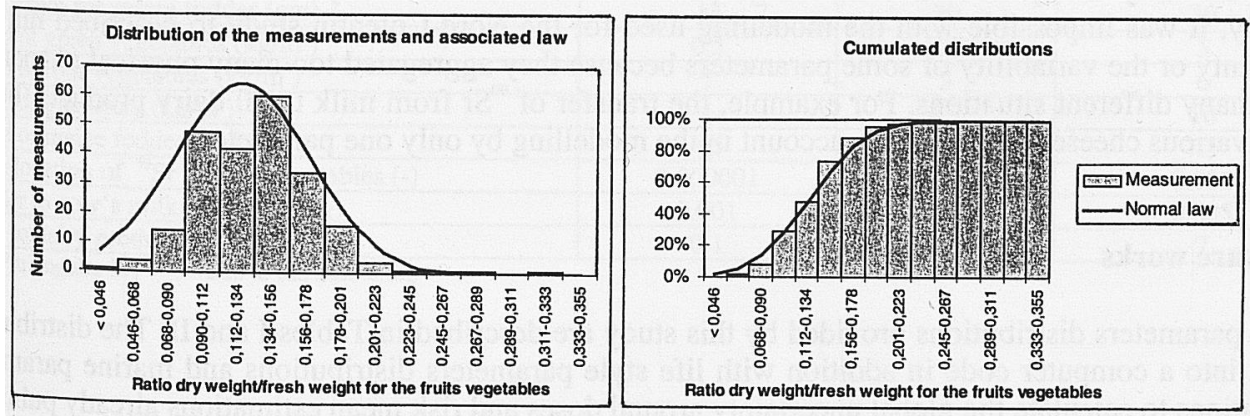

Figure 3: Treatment of the variability for the water content - the case of the fruits vegetables (229 results of measurements) 


\subsubsection{Carbon content of foodstuffs}

The carbon content of foodstuffs is the main parameter of the specific activity model used to calculate the transfer of carbon 14 in the terrestrial ecosystems. Very few data were available in the database because the measurement of ${ }^{14} \mathrm{C}$ is performed only recently in the vicinity of the French nuclear power plants. However, the data enabled to demonstrate that the variability of carbon content of foodstuffs is strongly linked with their water content variability. The next step was to choose the "best estimate" mean of the carbon content (grams of carbon per gram of dry matters) for each foods category. This choice relies upon bibliographic review of the radioecological modelling but also on dietetics knowledge. Then the distributions of carbon content (in fresh weight) were reconstructed for each food category by applying the variability of the corresponding water content distribution to the mean of the carbon content (in dry weight). The distributions obtained were normal laws.

\subsubsection{Soil to plant transfer factor}

The bibliographic knowledge on soil to plant transfer is very important and supported by numerous international reviews. Nowadays, there is a common agreement that the soil to plant transfer factors fit lognormal distributions. The international published values and especially the international database developed by the UIR [4] were therefore considered to reconstruct the lognormal distribution for this parameter. The soils of the Nord-Cotentin region were assumed to enter the category "loam soils" (less than $70 \%$ of sand and less than $35 \%$ of clay).

\subsection{Parameters without results of measurements}

This case was the most likely situation and required the expert judgment to be able to construct statistical laws for different kinds of parameters : agronomical parameters, transfer to vegetable parameters and transfer to animal and animals products parameters. For all these parameters, site-specific measurement results were not available and generic knowledge are not directly adapted to the Nord-Cotentin case. The main efforts were devoted to the identification of minimum and maximum values of the distributions to study the sensibility of these parameters. Of course we strongly relied upon bibliography and especially upon a previous similar study [5], but we also perform an in depth thinking about the real signification of each parameter of the transfer modelling. It appeared from the combination of these both ways of work that the extreme values identified correspond very often to physical limitations which can not be exceeded by the parameters. For example, it is impossible for a vegetable in French agricultural fields to grow faster than in 18 days. This first conclusion decided the experts to choice the triangular shape to build statistical laws for these parameters.

The study of the uncertainty of these parameters is less reliable than for the previous parameters due mainly to two reasons. Firstly, we decided to limit the efforts made on some of these parameters (for example for the agronomical parameters : yield, growing time, ...) because previous sensibility studies shown that they rarely account for a large part in the total uncertainty of the transfer model. And secondly, it was impossible with the modelling used for the Nord-Cotentin study to described fully the uncertainty or the variability of some parameters because they aggregated too many physical phenomena or too many different situations. For example, the transfer of ${ }^{90} \mathrm{Sr}$ from milk to all dairy products (butter, cream, various cheeses) is taken into account in the modelling by only one parameter.

\subsection{Future works}

All the parameters distributions provided by this study are described in Tables I and II. The distributions are put into a computer code in addition with life style parameters distributions and marine parameters distributions to calculate the global uncertainty around doses and risk mean estimations already published [2]. These calculations are currently underway. 
Ialle I: The statistical characteristics for each parameter's distribution studied - cases of the parameters with environmental measurements.

\begin{tabular}{|c|c|c|c|}
\hline Parameters & Distribution & Mean & Standard deviation \\
\hline Amospheric transfer parameter ratio $\left(\mathrm{s} \cdot \mathrm{m}^{-3} / \mathrm{s} \cdot \mathrm{m}^{-3}\right)$ & lognormal & 2.41 & 1.52 \\
\hline Water content of root vegetables (\%) & normal & 0.89 & 0.01 \\
\hline Whater content of cow's milk (\%) & normal & 0.855 & 0.05 \\
\hline Carbon content of fruits vegetables ( $\mathrm{gC} / \mathrm{fresh} \mathrm{kg}$ ) & normal & 60 & 19 \\
\hline Carbon content of root vegetables ( $\mathrm{gC} / \mathrm{fresh} \mathrm{kg}$ ) & normal & 75 & 24 \\
\hline Carbon content of beef ( $\mathrm{gC} / \mathrm{fresh} \mathrm{kg})$ & normal & 200 & 26 \\
\hline Carbon content of pork ( $\mathrm{gC} /$ fresh $\mathrm{kg}$ ) & normal & 300 & 39 \\
\hline Carbon content of poultry ( $\mathrm{gC} /$ fresh $\mathrm{kg}$ ) & normal & 150 & 20 \\
\hline Carbon content of eggs ( $\mathrm{gC} / \mathrm{fresh} \mathrm{kg}$ ) & normal & 150 & 20 \\
\hline Carbon content of cow's milk ( $\mathrm{gC} / \mathrm{fresh} \mathrm{kg}$ ) & normal & 67 & 6 \\
\hline Soil to plant : ${ }^{90} \mathrm{Sr}$ for green vegetables (dry/dry) & lognormal & 3.05 & 5.34 \\
\hline Soil to plant : ${ }^{90} \mathrm{Sr}$ for root vegetables (dry/dry) & lognormal & 2.81 & 17.34 \\
\hline Soil to plant : ${ }^{90} \mathrm{Sr}$ for potatoes (dry/dry) & lognormal & 0.275 & 0.050 \\
\hline Soil to plant : ${ }^{00} \mathrm{Sr}$ for grass/hay (dry/dry) & lognormal & 0.180 & 0.585 \\
\hline Soil to plant : ${ }^{\circ} \mathrm{Sr}$ for maize fodder (dry/dry) & lognormal & 0.487 & 0.242 \\
\hline Soil to plant : :97Tc for green vegetables (dry/dry) & lognormal & 0.086 & 0.013 \\
\hline
\end{tabular}

Table II: The statistical characteristics for each parameter's distribution studied - cases of the parameters without environmental measurements.

\begin{tabular}{|c|c|c|c|}
\hline Parameter & Minimum* & Mode* & Maximum* \\
\hline Half-time in soil for ${ }^{90} \mathrm{Sr}(/ \mathrm{an})$ & 0.03 & 0.07 & 0.14 \\
\hline Half-time in soil for ${ }^{99} \mathrm{Tc}(/ \mathrm{an})$ & 0.0023 & 11.55 & 23 \\
\hline Soil density (dry $\left.\mathrm{kg} / \mathrm{m}^{3}\right)$ & 540 & 952 & 1302 \\
\hline Interception ratio for green vegetables (-) & 0.2 & 0.25 & 0.3 \\
\hline Interception ratio for root vegetables $(-)$ & 0.3 & 0.4 & 0.5 \\
\hline Interception ratio for grass/hay (-) & 0.4 & 0.5 & 0.6 \\
\hline Interception ratio for maize fodder (-) & $\overline{0.4}$ & 0.5 & 0.6 \\
\hline Biological half-time of ${ }^{\text {s0 }} \mathrm{Sr}$ in green vegetables (/day) & 0.03 & 0.07 & 0.14 \\
\hline Biological half-time of ${ }^{90} \mathrm{Sr}$ in root vegetables (/day) & 0.03 & 0.07 & 0.14 \\
\hline Biological half-time of ${ }^{90} \mathrm{Sr}$ in grass/hay (/day) & 0.015 & 0.05 & 0.1 \\
\hline Biological half-time of ${ }^{80} \mathrm{Sr}$ in maize fodder (/day) & 0.03 & 0.07 & 0.14 \\
\hline Growing time for green vegetables (day) & 30 & 122 & 310 \\
\hline Growing time for root vegetables (day) & 18 & 85 & 180 \\
\hline Growing time for grass/hay (day) & \multicolumn{3}{|c|}{$365^{* *}$} \\
\hline Growing time for maize fodder (day) & 130 & 153 & 180 \\
\hline Root depth of green vegetables $(\mathrm{cm})$ & 10 & 20 & 30 \\
\hline Root depth of root vegetables $(\mathrm{cm})$ & 10 & 20 & 30 \\
\hline Root depth of grass/hay (cm) & 10 & 20 & 30 \\
\hline Root depth for maize fodder $(\mathrm{cm})$ & 15 & 20 & 30 \\
\hline Yield of green vegetables $\left(\mathrm{kg} / \mathrm{m}^{2}\right)$ & 0.5 & 2.7 & 5 \\
\hline Yield of root vegetables $\left(\mathrm{kg} / \mathrm{m}^{2}\right)$ & 1 & 3 & 6 \\
\hline Yield of grass $/ \mathrm{hay}\left(\mathrm{kg} / \mathrm{m}^{2}\right)$ & 1 & 4.2 & 10 \\
\hline Yield of maize fodder $\left(\mathrm{kg} / \mathrm{m}^{2}\right)$ & 4.5 & $\overline{5.5}$ & 7.5 \\
\hline Translocation of ${ }^{90} \mathrm{Sr}$ in root vegetables $(-)$ & 0.000001 & 0.00005 & 0.001 \\
\hline Fodder to cow's milk: ${ }^{90} \mathrm{Sr}$ (day $\left./ \mathrm{kg}\right)$ & 0.001 & 0.002 & 0.005 \\
\hline Milk to dairy products : ${ }^{\infty} \mathrm{Sr}(-)$ & 0.1 & 1 & 7 \\
\hline
\end{tabular}

* triangular law ** due to the modelling 


\section{CONCLUSIONS}

The parameters studied for the uncertainty analysis can be classified in two categories : the ones for which the available local measurements or the use of national measurements allowed to reconstruct their statistical distribution and the ones for which the available information and/or the structure of the modelling did not allow us to perform an in depth analysis of their variability and uncertainty. Based on the present knowledge, it seems unlikely that the parameters of the second category can account for a large part in the total uncertainty of the leukaemia risk calculation of the Nord-Cotentin study. However, when the results of the whole uncertainty calculations will be available, further efforts could be recommended to improve the knowledge of these parameters.

\section{References}

[1] Laurier D. and Bard D., Epidemiologic studies of leukaemia among persons under 25 years oid living near nuclear sites, Epidemiol. Rev. 21 (1999) 188-206.

[2] Rommens C., Laurier D. and Sugier A., Methodology and results of the Nord-Cotentin radioecological study, J. Radiol. Prot. 20 (2000) 361-380.

[3] Maro D., Baron Y., Gerlain P., Crabol B., Hebert D., Solier L. Utilisation du krypton 85 rejeté dans l'environnement par l'usine de retraitement de La Hague comme outil d'étude de la dispersion atmosphérique, rapport DPRE/SERNAT 99-14 (Institut de Protection et de Sûreté Nucléaire, Fontenayaux-Roses, 1999)

[4] Union Internationale des Radioécologistes (UIR), Vith report of the working group on soil to plant transfer factors. Report of the working group meeting at Guttannen, Grimselpass Switzerland, 24-26 May 1989.

[5] US. Nuclear Regulatory Commission (USNRC) - Commission of the European Community. Probabilistic accident consequences uncertainty analysis, food chain uncertainty assessment. Vol. 1 and 2. NUREG/CR-6523 - EUR 16771, 1997. 